\title{
Application of Various Surgical Techniques in Orthotopic Liver Transplantation: a 10-year Experience at a Single Center
}

\section{Zhitao Chen}

Sun Yat-sen University First Affiliated Hospital

Ming Han

Sun Yat-sen University First Affiliated Hospital

\section{Weiqiang Ju}

Sun Yat-sen University First Affiliated Hospital

Maogen Chen ( $\square$ chenmg3@mail.sysu.edu.cn )

Sun Yat-sen University First Affiliated Hospital

Xiaoshun He ( $\sim$ 490871362@qq.com )

Sun Yat-sen University First Affiliated Hospital

\section{Research article}

Keywords: surgical techniques, liver transplantation, mortality, prognosis

Posted Date: June 10th, 2020

DOI: https://doi.org/10.21203/rs.3.rs-31370/v1

License: (1) (1) This work is licensed under a Creative Commons Attribution 4.0 International License. Read Full License 


\section{Abstract}

\section{Background}

Liver transplantation (LT) is considered the only curative treatment for end-stage liver disease (ESLD), and the surgical techniques of LT have continually evolved and have been modified. In this study, we prospectively analyzed a single-center case series in our center and compared the advantages and disadvantages of each method.

\section{Methods}

In total, 1,029 patients with OLT at our department were enrolled in this study. The recipient perioperative data were assessed and analyzed. Three types of LT techniques were utilized: modified classic, modified piggy-back (MPB) and classic piggy-back (PB) orthotopic LT, corresponding to groups A, B and C.

\section{Results}

Cirrhosis was the most prevalent condition in group $B$, while tumors tended to be more common in group $A$. Patients in group $\mathrm{C}$ were in poorer general condition with higher creatinine, total bilirubin and PT-INR $(P=0.029$, 0.011 and 0.026 , respectively). Two hundred ninety-five patients had previous abdominal surgery, and the proportion was higher in group $\mathrm{B}(P=0.017)$. The cold ischemia time in group $\mathrm{B}$ was longer than those in the other two groups $(P<0.001)$. The mortality rate was $7.9 \%$ within 30 days and $11.7 \%$ within 90 days. Most of the deaths were not technique-related.

\section{Conclusion}

The advantages and disadvantages are different for these three surgical techniques. A reasonable operation technique should be adopted considering the patient's unique condition to ensure the stability of hemodynamics.

\section{Background}

LT is considered the only curative treatment for ESLD ${ }^{1}$. Currently, LT survival within one year can reach approximately $90 \%$ with progressive improvement in surgical methods, immunosuppressants and sepsis controls ${ }^{2}$. Furthermore, the surgical techniques of LT have continually evolved and have been modified ${ }^{3}$. In 1963, Starzl et al. initiated a technique for LT in which the superior (SHVC) and inferior hepatic vena cava (IHVC) and portal vein (PV) were completely blocked, and the retrohepatic inferior vena cava (RHIVC) was removed as a part of the diseased liver; it was named classic OLT ${ }^{4}$. However, the hemodynamics in the anhepatic phase is not stable, and reflux of the renal vein is blocked, causing renal dysfunction ${ }^{5}$. In 1989, Tzakis et al. ${ }^{6}$ described a novel technique called classic piggy-back (PB) LT. In this technique, the PHVC is preserved, the SHVC of the donor liver is anastomosed with a common opening formed by the left and middle hepatic veins of the recipient liver, and the IHVC of the donor liver is ligated. The flow during the anhepatic period and hemodynamic stability are maintained during the operation. The technique can also reduce the occurrence of renal failure after liver transplantation and is more beneficial to patients with cardiac insufficiency or a poor general condition. However, specific complications related to PB, such as outflow obstruction, can cause liver congestion, swelling and even delayed graft function (DGF) or transplanted liver failure. In 1992, Belghiti et al. ${ }^{7}$ developed the modified piggy-back (MPB) technique in which side-to-side cavocaval anastomosis is performed at the anterior face of the recipient RHIVC to minimize outflow obstruction. 
Wu. et al. ${ }^{8}$ also reported another MPB technique, which has the advantages of simplifying the steps of hepatectomy and separation, and the anastomosis of the vena cava is large, thereby avoiding outflow tract obstruction. However, this operation requires complete blockade of the inferior vena cava, and the anhepatic period is long, thereby leading to intraoperative hemodynamic instability and renal dysfunction.

The PB and MPB techniques are limited when the caudate lobe of the recipient liver is hypertrophied ${ }^{9}$. Particularly, in some patients with Budd-Chiari syndrome, the RHIVC is surrounded in the caudate lobe of the liver, making it difficult to preserve the inferior vena cava during hepatectomy ${ }^{10}$. Additionally, in patients with large liver cancers, the RHIVC tends to be resected, and classic LT is recommended ${ }^{11}$. To simplify the operation process and shorten the anhepatic period, we developed a modified classic LT technique ${ }^{12}$. In this technique, it is not necessary to free the IVC and dissect the posterior space of the IVC and right adrenal vein. The IVC is clamped directly from front to back and repaired after resection of the diseased liver. Next, it is sutured continually from front to back. Compared with conventional classic LT, it is easy to expose and convenient for the surgeon to anastomose.

In general, the selection of surgical techniques is dependent on the patient's conditions. In this study, we prospectively analyzed a single-center case series (1,029 cases) at our center and compared the advantages and disadvantages of each method.

\section{Methods}

In total, 1,029 patients who had undergone OLT at our department from January 2009 to December 2019 were enrolled in the study. The recipient pretransplantation data, including demographics, the results of preoperative laboratory examinations, model for end-stage live disease (MELD) score, Child-Pugh score, history, and diagnosis were collected. The perioperative data, including the anhepatic time, cold ischemia time, duration of operation, blood loss and transfusion of red blood cells (RBCs), fresh frozen plasma (FFP), and platelets, were recorded. Additionally, postoperative surgical complications, length of stay in the intensive care unit (ICU), and the mortality rates and cause of death within the postoperative 30 days were assessed and analyzed.

\section{Surgical techniques}

\section{Modified classic technique}

This technique is an improvement of classical orthotopic LT. First, the common bile duct, hepatic artery and portal vein were dissociated in turn for dissection of the first hepatic hilum. Thereafter, the left triangular ligament, hepatogastric ligament and right triangular ligament were separated and the RHIVC was dissociated. The differences from the conventional method are that dissociating the IVC is unnecessary and the blocking direction was from front to back. The donor's and recipient's IVC were fixed together at 0 and 6 o'clock using two 4-0 Prolene lines. The suture was continuous from back to front. The patients who had undergone this technique were enrolled in group $A$.

\section{MPB technique}

The dissection of the first hepatic hilum and peri-hepatic ligaments was the same as that in the convention technique. Subsequently, the SIVC and PIVC were dissociated and then immediately blocked. The diseased liver was resected close to the anterior wall of the IVC, and all short hepatic veins were ligated. Thereafter, the openings of the three hepatic veins were cut and reshaped, and the anterior wall of the IVC was cut longitudinally to form a 
large triangular outlet. Anastomosis was performed between the outlet of the recipient IVC and matched the opening of the SVC in the donor liver. The IHVC of the donor liver was ligated before reperfusion. The patients who had undergone this technique were enrolled in group $B$.

\section{PB technique}

This technique was described as the standard back-table procedure for the liver. The dissection of the first hepatic hilum and peri-hepatic ligaments was the same as that in the conventional technique. The short hepatic veins in the third hepatic hilum were ligated so the right, left and middle hepatic veins (RHV, LHV and MHV) were exposed. The diseased liver was then resected after ligation of the RHV and blockade of the LHV as well as the MHV. Anastomosis was performed between the recipient SVC and the reshaped common trunk of the LHV and MHV of the donor liver. During the entire operation, the blood flow in the IVC was maintained. The patients who had undergone this technique were enrolled in group $\mathrm{C}$.

\section{Postoperative management}

Basiliximab was used for induction during the operation and postoperative day (POD) 4. The immunosuppressive regimen was tacrolimus (Tac) and mycophenolate mofetil (MMF). Corticosteroid therapy was not included in the routine regimen because of its side effects. The blood concentration of Tac was controlled at 8 to $15 \mathrm{ng} / \mathrm{ml}$ in the early stage after the operation. Routine Doppler ultrasound of the liver graft blood flow and biliary tract was performed once every 2 days for 7 days. Thereafter, imaging studies were performed based on the patients' clinical status or laboratory findings.

\section{Statistical analysis}

All the statistical analyses of the data were performed using SPSS version 26.0. All the data were expressed as means \pm standard deviation or numbers and percentages of patients. For comparison between groups, chi-square and Fisher's exact tests were performed for frequencies and continuous data, respectively. The Cox proportional hazards model was used for multivariate analysis. A $P$-value $<0.05$ was considered to be significant.

\section{Results}

We performed 1,029 OLTs at our center from January 2009 to December 2019. Three hundred eighteen patients had undergone the modified classic technique (group A), 592 had undergone the modified MPB technique (group B), and 119 had undergone the PB technique (group C). The baseline data (gender, age, height and weight) of the patients among the groups were similar (Table 1 ). The male to female ratio was 6.74 , and the mean age was 48.48 \pm 0.40 years. Patients in group $\mathrm{C}$ were in poorer general condition with higher creatinine, total bilirubin and PT-INR $(P=0.029,0.011$ and 0.026 , respectively), and other indexes were similar. The mean MELD score and Child-Pugh score were $17.02 \pm 0.30$ and $8.44 \pm 0.07$, respectively. These values were significantly higher in group $C$. Two hundred ninety-five patients had a previous abdominal surgery, and the proportion was higher in group $\mathrm{B}(P=$ 0.017). Seven hundred forty-four patients were diagnosed with cirrhosis, and 594 were diagnosed with tumors. Cirrhosis was the most prevalent condition in group $\mathrm{B}$, while tumors tended to be more common in group $\mathrm{A}(P=$ 0.023 and $<0.001$, respectively). 
Table 1

Preoperative Data for Patients Transplanted in Different Techniques ( $\mathrm{n}=1029)$

\begin{tabular}{|c|c|c|c|c|c|c|}
\hline \multicolumn{7}{|c|}{ Surgical Techniques } \\
\hline & Total & A & B & C & $\chi^{2}$ & $P$ \\
\hline & $(n=1029)$ & $(n=318)$ & $(n=592)$ & $(n=119)$ & & \\
\hline Gender(male/female) & $896 / 133$ & $287 / 31$ & $511 / 81$ & $98 / 21$ & & 0.064 \\
\hline Age(ys) & $48.48 \pm 0.40$ & $48.51 \pm 0.70$ & $48.10 \pm 0.53$ & $50.28 \pm 1.11$ & & 0.233 \\
\hline Height(cm) & $166.69 \pm 0.44$ & $167.13 \pm 0.76$ & $166.24 \pm 0.64$ & $\begin{array}{l}167.73 \pm \\
0.64\end{array}$ & & 0.467 \\
\hline Weight(kg) & $64.81 \pm 044$ & $64.68 \pm 0.73$ & $64.84 \pm 0.62$ & $64.99 \pm 1.07$ & & 0.977 \\
\hline Creatinine(umol/L) & $88.16 \pm 2.44$ & $89.66 \pm 3.76$ & $84.03 \pm 3.05$ & $\begin{array}{l}104.67 \pm \\
10.67\end{array}$ & & 0.029 \\
\hline Albumin(g/L) & $36.38 \pm 0.38$ & $35.74 \pm 0.40$ & $36.74 \pm 0.61$ & $36.30 \pm 0.72$ & & 0.495 \\
\hline Total bilirubin (umol/L) & $149.20 \pm 6.34$ & $\begin{array}{l}138.71 \pm \\
10.82\end{array}$ & $144.37 \pm 8.30$ & $\begin{array}{l}201.30 \pm \\
21.05\end{array}$ & & 0.011 \\
\hline PT-INR & $1.73 \pm 0.07$ & $1.55 \pm 0.05$ & $1.72 \pm 0.09$ & $2.22 \pm 0.38$ & & 0.026 \\
\hline AFP (ng/mL) & $\begin{array}{l}15191.14 \pm \\
3905.31\end{array}$ & $\begin{array}{l}23223.54 \pm \\
9148.16\end{array}$ & $\begin{array}{l}12177.22 \pm \\
4544.37\end{array}$ & $\begin{array}{l}8719.96 \pm \\
5601.59\end{array}$ & & 0.374 \\
\hline MELD score & $17.02 \pm 0.30$ & $16.49 \pm 0.53$ & $16.62 \pm 0.38$ & $20.47 \pm 0.94$ & & $\varangle 0.001$ \\
\hline Child-Pugh score & $8.44 \pm 0.07$ & $8.20 \pm 0.13$ & $8.42 \pm 0.09$ & $9.12 \pm 0.22$ & & 0.001 \\
\hline \multicolumn{7}{|l|}{ History } \\
\hline $\begin{array}{l}\text { Respiratory diseases } n \\
(\%)\end{array}$ & $17(1.6)$ & $3(0.3)$ & $11(1.1)$ & $3(0.3)$ & 1.69 & 0.429 \\
\hline Hypertension n (\%) & 109(10.6) & $41(4.0)$ & $58(5.6)$ & $10(1.0)$ & 2.78 & 0.250 \\
\hline Diabetes n (\%) & $117(11.5)$ & $43(4.2)$ & $62(6.1)$ & $12(1.2)$ & 2.13 & 0.345 \\
\hline $\begin{array}{l}\text { Previous abdominal } \\
\text { surgery } \mathrm{n}(\%)\end{array}$ & 295(28.6) & $85(8.3)$ & 187(18.1) & $23(2.2)$ & 8.13 & 0.017 \\
\hline \multicolumn{7}{|l|}{ Diagnosis } \\
\hline Cirrhosis n (\%) & $744(72.3)$ & $247(24.0)$ & $418(40.6)$ & 79(7.7) & 7.51 & 0.023 \\
\hline Acute liver failure $n(\%)$ & $38(3.7)$ & $6(0.6)$ & $27(2.6)$ & $5(0.5)$ & 4.26 & 0.119 \\
\hline Tumor n (\%) & $594(57.7)$ & $218(21.2)$ & $322(31.3)$ & $54(5.2)$ & 25.409 & $\$ 0.001$ \\
\hline
\end{tabular}

We found that the cold ischemia time was significantly different among the three groups $(P<0.001)$. The time in group B was $455.60 \pm 6.20$ minutes, longer than those in other two groups $(414.20 \pm 10.47$ and $402.38 \pm 18.20$ minutes for groups $A$ and $C$, respectively). The anhepatic time and operation duration were similar in all the groups. We also noted a significant difference in intraoperative transfusion such that patients in group B had a larger 
transfusion volume of platelets $(P=0.029)$. The estimated blood loss and transfusion of FFP and RBC were similar in all the groups (Table 2).

Table 2

Operative Characteristics of Patients Transplanted in Different Techniques $(n=1029)$

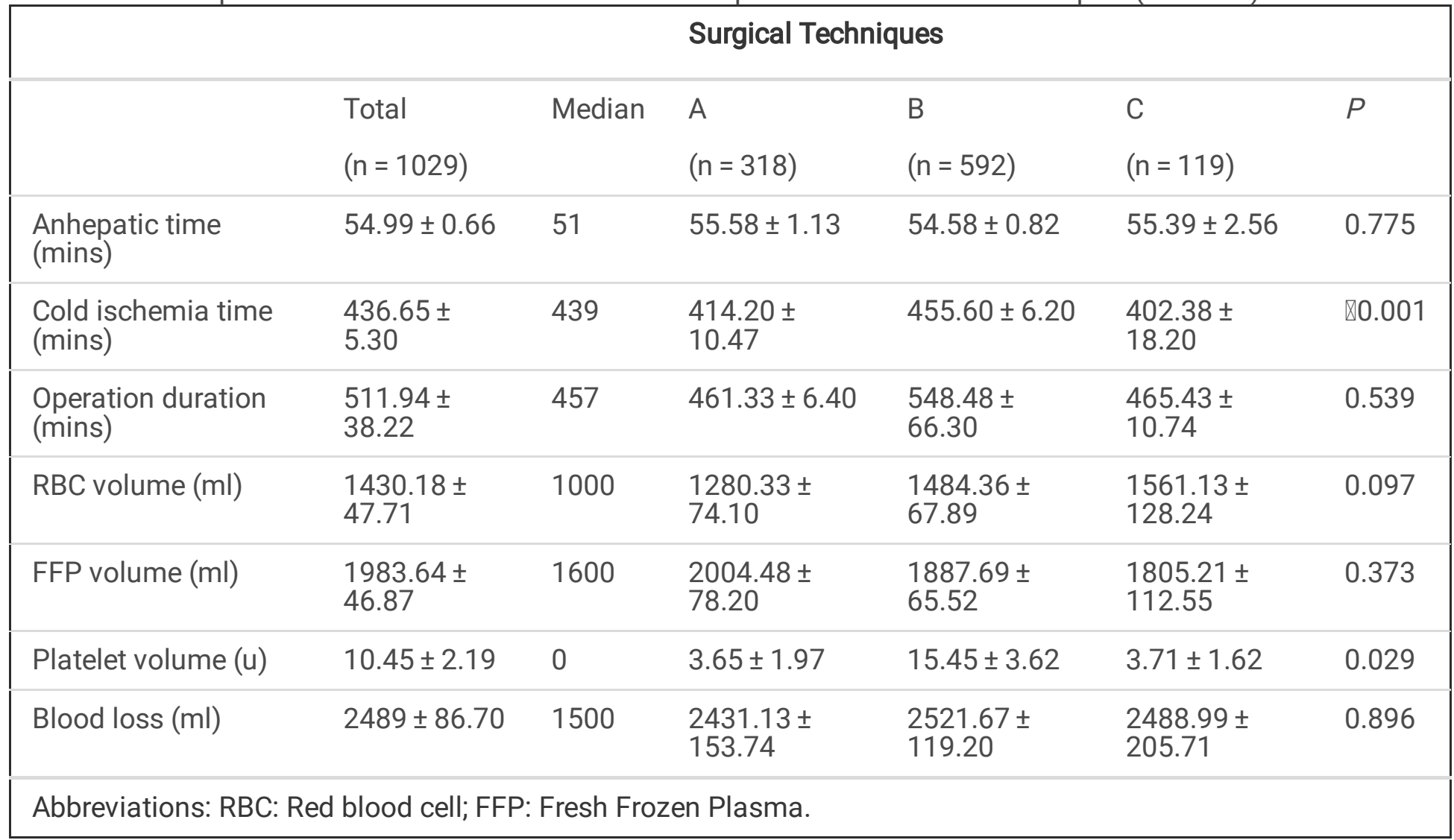

The extubation times were $61.44 \pm 16.34,39.16 \pm 3.62,49.26 \pm 7.40$ hours in groups $\mathrm{A}, \mathrm{B}$ and $\mathrm{C}$, respectively $(P=$ $0.195)$, the postoperative eating times were $129.20 \pm 8.36,124.61 \pm 4.78$ and $123.54 \pm 14.95$ hours, respectively $(P=$ 0.857), and the ICU durations were $94.02 \pm 16.76,71.46 \pm 5.59$ and $72.99 \pm 9.51$ hours, respectively $(P=0.250)$. The most frequent postoperative complications within 30 days in all patients was abdominal bleeding $(n=62,6.0 \%)$, followed by renal failure $(n=46,4.5 \%)$ and early allograft dysfunction $(n=35,3.4 \%)$. Notably, 3 patients had outflow obstruction (group B: $n=2,0.33 \%$; group $C: n=1,0.84 \% ; P=0.010$ ). No significantly differences were observed in other complications (Table 3). 
Table 3

Postoperative Values and Surgical Complications in Patients Transplanted with Different Techniques $(n=1029)$

\section{Surgical techniques}

\begin{tabular}{|c|c|c|c|c|c|c|}
\hline & $\begin{array}{l}\text { Total } \\
(n=1029)\end{array}$ & $\begin{array}{l}A \\
(n=318)\end{array}$ & $\begin{array}{l}B \\
(n=592)\end{array}$ & $\begin{array}{l}C \\
(n=119)\end{array}$ & Median $/ \chi^{2}$ & $P$ \\
\hline Extubation time (hr) & $47.22 \pm 5.53$ & $\begin{array}{l}61.44 \pm \\
16.34\end{array}$ & $39.16 \pm 3.62$ & $49.26 \pm 7.40$ & 14 & 0.195 \\
\hline Eating time (hr) & $\begin{array}{l}125.63 \pm \\
4.02\end{array}$ & $\begin{array}{l}129.20 \pm \\
8.36\end{array}$ & $\begin{array}{l}124.61 \pm \\
4.78\end{array}$ & $\begin{array}{l}123.54 \pm \\
14.95\end{array}$ & 100 & 0.857 \\
\hline ICU stay time (hr) & $78.62 \pm 6.20$ & $\begin{array}{l}94.02 \pm \\
16.76\end{array}$ & $71.46 \pm 5.59$ & $72.99 \pm 9.51$ & 35 & 0.250 \\
\hline $\begin{array}{l}\text { Abdominal bleeding } n \\
(\%)\end{array}$ & $62(6.0)$ & $19(1.8)$ & $37(3.6)$ & $6(0.6)$ & 0.257 & 0.879 \\
\hline HAT n (\%) & $23(2.2)$ & $7(0.7)$ & $15(1.5)$ & $1(0.1)$ & 1.303 & 0.521 \\
\hline PVT n (\%) & $10(1.0)$ & $2(0.2)$ & $7(0.7)$ & $1(0.1)$ & 0.683 & 0.711 \\
\hline $\begin{array}{l}\text { Outflow obstruction n } \\
(\%)\end{array}$ & $3(0.3)$ & 0 & $1(0.1)$ & $2(0.2)$ & 9.135 & 0.010 \\
\hline PNF n (\%) & $12(1.2)$ & $5(0.5)$ & $4(0.4)$ & $3(0.3)$ & 3.59 & 0.166 \\
\hline EAD n (\%) & $35(3.4)$ & $17(1.7)$ & $15(1.5)$ & $3(0.3)$ & 5.297 & 0.071 \\
\hline AKI n (\%) & $46(4.5)$ & $15(1.5)$ & $26(2.5)$ & $5(0.5)$ & 0.074 & 0.964 \\
\hline Death in 30 days $n(\%)$ & $82(7.9)$ & $22(2.1)$ & $51(5.0)$ & $9(0.9)$ & 0.842 & 0.656 \\
\hline Death in 90 days $\mathrm{n}(\%)$ & 121(11.7) & $32(3.1)$ & $75(7.3)$ & $14(1.3)$ & 1.354 & 0.508 \\
\hline
\end{tabular}

In all the patients, the mortality rate was $7.9 \%$ within 30 days and $11.7 \%$ within 90 days (Table 3 ). The mortality rates within 30 days in groups $A, B$ and $C$ were $6.9 \%, 8.6 \%$ and $7.6 \%$, respectively. The mortality rates within 90 days in groups $A, B$ and $C$ were $10.0 \%, 12.7 \%$ and $11.8 \%$, respectively. The most frequent causes of death were multiple organ dysfunction syndrome (MODS) (within 30 days: $n=56,68.3 \%$; within 90 days: $n=84,69.4 \%$ ) in all the patients (Table 4). Vena cava obstruction was significantly different in group $C(P=0.016$ and 0.021 , respectively). In multivariable analysis, we found that abdominal bleeding, portal vein thrombosis (PVT), early allograft dysfunction (EAD) and acute kidney injury (AKI) were independent factors impacting survival within 30 days, and respiratory diseases, abdominal bleeding, hepatic artery thrombosis (HAT), PVT, primary nonfunction (PNF), EAD, AKI were independent factors impacting survival within 90 days (Table 5). 
Table 4

Analysis for Causes of Death within 30 Days and 90 Days Patients Transplanted with Different Techniques

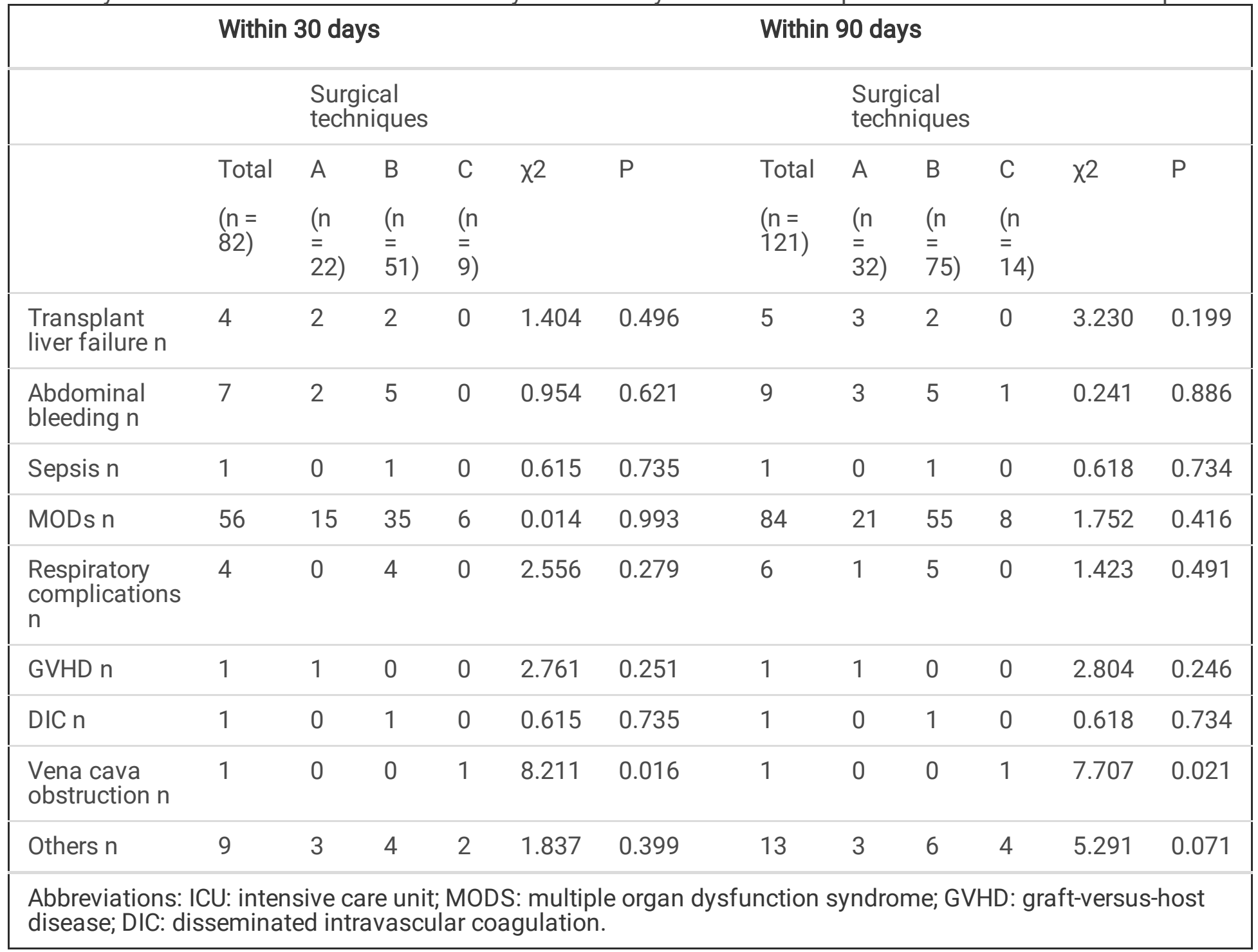


Table 5

Multivariant analysis on Cause of Death within 30 Days and 90 Days Patients Transplanted with Different Techniques

\begin{tabular}{|c|c|c|c|c|}
\hline \multirow[t]{3}{*}{ Variants } & \multicolumn{4}{|l|}{ Multivariant analysis } \\
\hline & 30 days & & 90 days & \\
\hline & $\mathrm{RR}(95 \% \mathrm{Cl})$ & $P$ & RR $(95 \% \mathrm{Cl})$ & $P$ \\
\hline Surgical techniques & $0.986(0.879 \sim 1.106)$ & 0.806 & $1.110(0.819 \sim 1.504)$ & 0.503 \\
\hline Respiratory diseases & 1.098 (0.673 1.792) & 0.708 & $2.882(1.134 \sim 7.321)$ & 0.026 \\
\hline Hypertension & $1.123(0.912 \sim 1.384)$ & 0.275 & $1.092(0.607 \sim 1.962)$ & 0.770 \\
\hline Diabetes & $0.927(0.757 \sim 1.135)$ & 0.462 & $1.222(0.679 \sim 2.198)$ & 0.504 \\
\hline Previous abdominal surgery & $1.021(0.889 \sim 1.173)$ & 0.770 & $1.072(0.692 \sim 1.660)$ & 0.755 \\
\hline Cirrhosis & $1.010(0.870 \sim 1.172)$ & 0.896 & $0.735(0.471 \sim 1.147)$ & 0.176 \\
\hline Acute liver failure & $0.856(0.601 \sim 1.219)$ & 0.387 & $2.296(1.115 \sim 4.726)$ & 0.024 \\
\hline Tumor & $1.141(1.000 \sim 1.303)$ & 0.050 & $0.981(0.649 \sim 1.485)$ & 0.930 \\
\hline Abdominal bleeding & $1.427(1.089 \sim 1.871)$ & 0.010 & $2.291(1.326 \sim 3.959)$ & 0.003 \\
\hline HAT & $0.899(0.592 \sim 1.366)$ & 0.618 & $2.524(1.037 \sim 6.142)$ & 0.041 \\
\hline PVT & $2.303(1.224 \sim 4.334)$ & 0.010 & $3.216(1.301 \sim 7.949)$ & 0.011 \\
\hline Outflow obstruction & $2.347(0.728 \sim 7.563)$ & 0.153 & $2.633(0.531 \sim 13.063)$ & 0.236 \\
\hline PNF & 20.471 (10.597 39.544) & $\otimes 0.001$ & 8.850(4.094 19.132) & $\bowtie 0.001$ \\
\hline EAD & $1.516(1.060 \sim 2.170)$ & 0.023 & $3.640(1.996 \sim 6.636)$ & $\otimes 0.001$ \\
\hline AKI & 1.837 (1.347 2.505) & $凶 0.001$ & $5.495(3.247 \sim 9.300)$ & $₫ 0.001$ \\
\hline
\end{tabular}

\section{Discussion}

LT is considered the most effective and only curative treatment for patients with ESLD. Many factors play an important role in the outcome of LT. Technique-related factors, including operative duration, intraoperative bleeding, and complications, are the most important. Most patients undergoing LT in China are complicated with portal hypertension, causing extensive collateral circulation between the PV and vena cava. Therefore, hemodynamic instability, such as bleeding during the operation, higher PV pressure during the anhepatic period and lower peripheral vascular resistance, more commonly occur and affect the success of the operation and postoperation survival. Over the decades, the surgical techniques of LT have continually evolved and have been modified. In summary, the difference among the techniques mainly concerns whether to block the RIHVC, which is the main factor affecting the hemodynamics in the anhepatic phase. 
The classic technique was first described and applied in operations by Strazl et al., and it remains applicable for some specific situations, such as caudate lobe hypertrophy and large liver cancers. However, blocking the RHIVC completely could lead to total interruption of venous return, hemodynamic instability, and renal failure ${ }^{13}$. Compared with the classic technique, the PB technique established by Tzakis et al. has several advantages, such as avoiding IVC anastomosis, leading to shortening of the anhepatic phase and total operative time. Nevertheless, hepatic venous outflow obstruction is the main complication due to the inappropriate size of the hepatic vein outlet ${ }^{14}$. The incidence of venous outflow obstruction was reported to be $4.6 \%{ }^{15}$. The MPB technique was designed as a side-toside cavocaval anastomosis instead of an end-to-end one and could reduce the risk of upper caval outflow obstruction. Several modifications were reported ${ }^{16}$. MPB has now become the main surgical method in most centers in China. However, this technique remains limited, especially in some patients with Budd-Chiari syndrome or if the inferior vena cava is surrounded by the caudate lobe of the liver, making it difficult to retain the IVC during hepatectomy. In some patients with large liver cancers, many scholars tend to remove the inferior vena cava after hepatectomy ${ }^{17}$. Our center developed a modified classic LT to simplify the operation process, shorten the anhepatic time and ensure radical treatment. Zoltan et al. ${ }^{18}$ reported that $50 \%$ of PB techniques and $40.5 \%$ classic techniques were performed as standard techniques in European transplantation centers. Therefore, a reasonable operation technique based on the patient's condition is of great significance to improve the prognosis of the patients. In this study, we prospectively analyzed the data of patients who had undergone LT at our center and compared the advantages and disadvantages of each method.

Many patients are diagnosed with liver cirrhosis in China, and the annual incidence is $2 \% \sim 10 \% 19$. The annual incidence of decompensated cirrhosis progressed to decompensated cirrhosis is $3-5 \%$, and the 5 -year survival rate of decompensated cirrhosis is $14-35 \%$. The annual incidence of HCC in patients with liver cirrhosis is $3-6 \% 20$. In our study, tumors and cirrhosis tended to be the most prevalent conditions in groups A and C, respectively. MPB would be the optimal choice for patients with nontumor-related ESLD. A large proportion of the tumors in the advanced-stage patients tend to undergo surgical resection or conservative treatment due to economic or ideological reasons, even if the tumors are detected early. LT would be considered only when other treatments were ineffective or if the tumor progressed. Thus, the modified classic OLT would be more radical.

The mean operation duration at our center was $511.94 \pm 38.22$ minutes, and no significant difference was found among the groups. Compared with previous national reports (range: $320-708$ minutes) ${ }^{21-23}$, our data for the MPB technique ( $548.48 \pm 66.30$ minutes) in group B were consistent with the international data. The mean duration in our cases was $461.33 \pm 6.40$ and $465.43 \pm 10.74$ minutes in groups $A$ and $C$, respectively. This result is acceptable compared with that in the randomized trial conducted by Cavallari et al. ${ }^{24}$ in which the operative time was $506 \pm 85$ minutes and $462 \pm 87$ minutes in the PB and conventional groups, respectively. A larger proportion of patients with previous abdominal surgery in group B may explain the longer operative time. The cold ischemia time is an inherent and unavoidable factor in LT. Egea-Guerrero et al. ${ }^{25}$ reported that a long ischemia time ( $\nabla 6$ hours) leads to a higher rate of complications after LT. The mean cold ischemia time in this study was 436.65 minutes and comparable with that in previous reports ${ }^{26}$. The longer cold ischemia time in group B may also be due to the history of abdominal surgery. The anhepatic phase is defined as the time from the dissection of the recipient liver to reperfusion of the graft. The length of the anhepatic time is variable, depending on the surgical technique. Stuart et al. ${ }^{27}$ concluded that the anhepatic phase would increase blood loss because of the absence of hepatic synthesis and clearance. Alexander et al. ${ }^{28}$ revealed that a long anhepatic phase duration (> 100 minutes) is an independent risk factor for graft dysfunction in LT. In his study, the median anhepatic time was 71 minutes. In our study, the

Page $10 / 16$ 
median and mean anhepatic times were 51 and $54.99 \pm 0.66$ minutes, respectively, and it was similar in all the groups $(P=0.775)$. This result may suggest that the modified classic LT technique could achieve comparable anhepatic times as PB or MPB because of its simplified procedure compared with the classic technique.

We previously reported a new technique to ensure the complete avoidance of ischemia injury during transplantation, defined as ischemia-free liver transplantation (IFLT) ${ }^{29}$. The donor liver is procured, preserved, and implanted under continuous NMP without a cold perfusion process. The cold ischemia time is theoretically shortened even to 0 . The results showed that it had obvious advantages in the recovery of allograft function and reduction of complications compared with the conventional procedure. A randomized clinical trial (RCT) was also performed to confirm its feasibility (ChiCTR1900021158).

According to our study, the median intraoperative blood loss, transfusion of RBCs, and FFP were 1500, 1000 and $1600 \mathrm{ml}$, respectively, and they were similar in all the groups. A larger transfusion volume of platelets was performed in group $B$ and was within an acceptable range compared with the experience at other centers ${ }^{30,31}$. In a cohort study of over 5,000 patients in France, Savier et al. ${ }^{32}$ found that the median ICU duration after LT was 8 days ( $5 \sim 15$ days). Arianeb et al. ${ }^{23}$ reported a 14-day ICU and IMC stay in their experience of 500 LTs using the MPB technique. In our study, the median and mean ICU stay time were 35 and $78.62 \pm 6.20$ hours, respectively, markedly shorter than previous experiences. Our center promoted the concept of 'enhanced recovery after surgery' (ERAS) to achieve early extubation, early functional exercise, and a shortened length of stay at the hospital ${ }^{33}$.

Complications in the early postoperative period are important concerns in LT. In our study, $6.0 \%$ of the patients had abdominal bleeding, and it was the most frequent postoperative complication. Abdominal bleeding is related to the preoperative patients' condition, operation techniques and postoperative anticoagulation ${ }^{34,35}$. Nobuhisa et al. ${ }^{36}$ reported that a higher MELD score, intraoperative blood loss and low fibrinogen value increase the incidence of postoperative abdominal bleeding. Our result revealed that it was not significantly different among the different techniques.

AKI was another prevalent complication, and its incidence was $4.5 \%$ in our study. The incidence of AKI in previous reports ranged from $0-16.7 \% 37,38$. AKI was mainly caused by hemodynamic instability, IVC blockade, and severe intraoperative blood loss. Hesse et al. ${ }^{37}$ showed that the incidence of postoperative renal dysfunction was significantly lower in the MPB group. However, no significant difference was found in the incidence of renal failure among the different groups in our study $(4.7 \%, 4.4 \%$ and $4.2 \%$ in groups $\mathrm{A}, \mathrm{B}$ and $\mathrm{C}$, respectively; $P=0.964)$. The cause may be that, although the IVC was blocked during the operation in group $A$, the operation process was simplified and the operative time was shortened, leading to little effect on the hemodynamic stability ${ }^{39}$.

Notably, outflow obstruction occurred in both groups B and C, with incidences of $0.16 \%$ and $1.68 \%$, respectively. Joel et al. ${ }^{40}$ reported that $2.0 \%$ of 253 patients with PB had outflow obstruction. An enlarged caudate lobe, oversized donor graft, abnormalities of the IVC, or adhesions between the liver and the RHIVC may be the main obstacles for the use of the PB or MPB technique ${ }^{41}$. At our center, the donor IVC was trimmed in a triangle-shaped fashion to avoid obstruction of hepatic venous outflow. Additionally, the incision on the IVC should have sufficient distance from the hepatic veins.

The early (within 30 days) and intermediate (within 90 days) mortality rates in all cases were $7.9 \%$ and $11.7 \%$, respectively. The most frequent causes of death were MODS. One case in group $\mathrm{C}$ died because of vena cava obstruction. Overall, most of the deaths were not technique related. In a previous report, approximately $10.9 \%$ had 
graft failure within 30 days $^{42}$. In another study, Alberto et al. reported the estimated 30-day mortality rate of over 3,000 LTs was $8.4 \%{ }^{43}$. Additionally, they also mentioned that patients with PVT had a higher mortality rate of 12.4 $\sim 17.7 \% 44,45$. HAT and PNF were also the main causes of death for the reported patients according to the findings of Khan et al. ${ }^{46}$. In multivariable analysis for our cases, we also found the above complications were the independent factors impacting survival.

\section{Conclusion}

Different surgical techniques have specific advantages and disadvantages. MPB or PB would be the optimal choice for patients with nontumor-related ESLD. For patients with advanced tumors, the modified classic OLT would be more radical. Our modified classic technique could achieve the same operation duration, including the cold ischemia time and total operative time, as MPB or PB and was proven to be as feasible as the classic method. A lower incidence of AKI in every group proved that hemodynamic stability should be maintained during the operation. Outflow obstruction persisted in MPB or PB; thus, the technique should be modified such that the incision on the IVC should have sufficient distance from the hepatic veins to avoid obstruction of hepatic venous outflow. At our center, most of the deaths were not technique-related; thus, preoperative general condition adjustment and postoperative management need to be further innovated to reduce mortality. IFLT may be the mainstream technique in the future because of its advantages. Therefore, a reasonable operation technique based on the patient's condition to ensure the stability of hemodynamics during the operation is of considerable significance to improve the prognosis.

\section{Abbreviations}

AKI: acute kidney injury; DGF: delayed graft function; EAD: early allograft dysfunction; ERAS: enhanced recovery after surgery; ESLD: end-stage liver disease; FFP: fresh frozen plasma; HAT: hepatic artery thrombosis; ICU: intensive care unit; IFLT: ischemia-free liver transplantation; IHVC: inferior hepatic vena cava; LHV: left hepatic vein; LT: liver transplantation; MELD: model for end-stage liver disease; MHV: middle hepatic veins; MMF: mycophenolate mofetil; MODS: multiple organ dysfunction syndrome; MPB: modified piggy-back; OLT: Orthotopic Liver Transplantation PB: piggy-back; PNF: primary nonfunction; PV: portal vein; PVT: portal vein thrombosis; RBCs: red blood cells; RCT: randomized clinical trial; RHIVC: retrohepatic inferior vena cava; RHV: right hepatic vein; SHVC: superior hepatic vena cava; Tac: tacrolimus

\section{Declarations}

\section{Ethics approval and consent to participate}

All the procedures were performed in accordance with the ethical standards of the IEC for Clinical Research and Animal Trials of the First Affiliated Hospital of Sun Yat-sen University on human experimentation (institutional and national) and with the Helsinki Declaration of 1964 and later versions. All the organs used in our study were from organ donation, and none was from executed prisoners. Written informed consent was obtained from all the patients before they were included in the study.

\section{Consent for publication}

Not applicable. 


\section{Availability of data and materials}

The datasets generated and/or analysed during the current study are available in the China liver transplantation Registration Center (CLTR), https://cltr.cotr.cn/.

\section{Competing interests}

The authors declare that they have no competing interests.

\section{Funding}

This work was supported by the National Natural Science Foundation of China (81401324 and 81770410), Guangdong Basic and Applied Basic Research Foundation (2020A1515011557), China and the funders (Xiaoshun He and Maogen Chen) were both corresponded for this study.

\section{Authors contribution}

Conceptualization: MC

Methodology: MC and XH

Writing - Original Draft: $\mathrm{ZC}$ and $\mathrm{MH}$

Writing - Review \& Editing: MC and XH

Supervision: WJ

Project administration: $\mathrm{XH}$

Funding acquisition: $\mathrm{MC}$ and $\mathrm{XH}$

\section{Acknowledgements}

Not applicable.

\section{References}

1. Morris PJ. Transplantation-a medical miracle of the 20th century. N Engl J Med. 2004;351(26):2678-80.

2. Meirelles Junior RF, Salvalaggio P, Rezende MB, Evangelista AS, Guardia BD, Matielo CE, et al. Liver transplantation: history, outcomes and perspectives. Einstein (Sao Paulo). 2015;13(1):149-52.

3. Mehrabi A, Fonouni H, Müller SA, Schmidt J. Current concepts in transplant surgery: liver transplantation today. Langenbecks Arch Surg. 2008;393(3):245-60.

4. Starzl TE, Marchioro TL, Porter KA, Brettschneider L. Homotransplantation of the liver. Transplantation. 1967;5(4):uppl:790-803.

5. Estrin JA, Belani KG, Ascher NL, Lura D, Payne W, Najarian JS. Hemodynamic changes on clamping and unclamping of major vessels during liver transplantation. Transplant Proc. 1989;21(3):3500-5.

6. Tzakis A, Todo S, Starzl TE. Orthotopic liver transplantation with preservation of the inferior vena cava. Ann Surg. 1989;210(5):649-52. 
7. Belghiti J, Panis Y, Sauvanet A, Gayet B, Fékété F. A new technique of side to side caval anastomosis during orthotopic hepatic transplantation without inferior vena caval occlusion. Surg Gynecol Obstet. 1992;175(3):270-2.

8. Wu YM, Voigt M, Rayhill S, Katz D, Chenhsu RY, Schmidt W, et al. Suprahepatic venacavaplasty (cavaplasty) with retrohepatic cava extension in liver transplantation: experience with first 115 cases. Transplantation. 2001;72(8):1389-94.

9. Busque S, Esquivel CO, Concepcion W, So SK. Experience with the piggyback technique without caval occlusion in adult orthotopic liver transplantation. Transplantation. 1998;65(1):77-82.

10. Navarro F, Le Moine MC, Fabre JM, Belghiti J, Cherqui D, Adam R, et al. Specific vascular complications of orthotopic liver transplantation with preservation of the retrohepatic vena cava: review of 1361 cases. Transplantation. 1999;68(5):646-50.

11. Lerut J, Ciccarelli O, Roggen F, Laterre PF, Danse E, Goffette P, et al. Cavocaval adult liver transplantation and retransplantation without venovenous bypass and without portocaval shunting: a prospective feasibility study in adult liver transplantation. Transplantation. 2003;75(10):1740-5.

12. He XS, Wu LW, Ju WQ, Tai Q, Han M, Wang DP, et al. [Selection of four surgical techniques in orthotopic liver transplantation]. Zhongguo Yi Xue Ke Xue Yuan Xue Bao. 2008;30(4):426-9.

13. Cherqui D, Lauzet JY, Rotman N, Duvoux C, Dhumeaux D, Julien M, et al. Orthotopic liver transplantation with preservation of the caval and portal flows. Technique and results in 62 cases. Transplantation. 1994;58(7):793-6.

14. Stieber AC, Gordon RD, Bassi N. A simple solution to a technical complication in "piggyback" liver transplantation. Transplantation. 1997;64(4):654-5.

15. Cescon M, Grazi GL, Varotti G, Ravaioli M, Ercolani G, Gardini A, et al. Venous outflow reconstructions with the piggyback technique in liver transplantation: a single-center experience of 431 cases. Transpl Int. 2005;18(3):318-25.

16. Liu C, Loong CC, Hsia CY, Tsai HL, Wei CF. "Modified side-to-side cavocaval anastomosis in selected cases of orthotopic liver transplantation". Surgery. 2007;142(1):123-4.

17. Lee LY, Foley DP. Technical Aspects of Orthotopic Liver Transplantation for Hepatocellular Carcinoma. Surg Clin North Am. 2016;96(2):269-81.

18. Czigany Z, Scherer MN, Pratschke J, Guba M, Nadalin S, Mehrabi A, et al. Technical Aspects of Orthotopic Liver Transplantation-a Survey-Based Study Within the Eurotransplant, Swisstransplant, Scandiatransplant, and British Transplantation Society Networks. J Gastrointest Surg. 2019;23(3):529-37.

19. [The guidelines of prevention and treatment for chronic hepatitis B (2019 version)]. Zhonghua Gan Zang Bing Za Zhi 2019, 27(12):938-961.

20. Fattovich G, Bortolotti F, Donato F. Natural history of chronic hepatitis B: special emphasis on disease progression and prognostic factors. J Hepatol. 2008;48(2):335-52.

21. Zieniewicz K, Krawczyk M, Nyckowski P, Pawlak J, Michałowicz B, Paluszkiewicz R, et al. Liver transplantation: comparison of the classical orthotopic and piggyback techniques. Transplant Proc. 2002;34(2):625-7.

22. Durand F, Aschehoug J, Sauvanet A, Bernuau J, Benhamou JP, Erlinger S, et al. Preservation of renal perfusion and postoperative renal function by side-to-side cavo-caval anastomosis in liver transplant recipients. Transpl Int. 1995;8(5):407-10. 
23. Mehrabi A, Mood ZA, Fonouni H, Kashfi A, Hillebrand N, Müller SA, et al. A single-center experience of 500 liver transplants using the modified piggyback technique by Belghiti. Liver Transpl. 2009;15(5):466-74.

24. Jovine E, Mazziotti A, Grazi GL, Ercolani G, Masetti M, Morganti M, et al. Piggy-back versus conventional technique in liver transplantation: report of a randomized trial. Transpl Int. 1997;10(2):109-12.

25. Ruiz de Azúa-López Z, Naranjo-Izurieta JR, Lameirao J, Martín-Villén L, Porras-López M, Palomo-Lopez N, et al. Cold Ischemia Time as a Factor in Post-transplantation Complications for Orthotopic Hepatic Transplantation. Transplant Proc. 2018;50(2):637-9.

26. Chen XB, Xu MQ. Primary graft dysfunction after liver transplantation. Hepatobiliary Pancreat Dis Int. 2014;13(2):125-37.

27. Cleland S, Corredor C, Ye JJ, Srinivas C, McCluskey SA. Massive haemorrhage in liver transplantation: Consequences, prediction and management. World J Transplant. 2016;6(2):291-305.

28. Ijtsma AJ, van der Hilst CS, de Boer MT, de Jong KP, Peeters PM, Porte RJ, et al. The clinical relevance of the anhepatic phase during liver transplantation. Liver Transpl. 2009;15(9):1050-5.

29. He X, Guo Z, Zhao Q, Ju W, Wang D, Wu L, et al. The first case of ischemia-free organ transplantation in humans: A proof of concept. Am J Transplant. 2018;18(3):737-44.

30. Wang HZ, Dong JH, Wang SG, Bie P, Cai JX, Lu Q. Modified hepatic outflow tract reconstruction in piggyback liver transplantation. Hepatobiliary Pancreat Dis Int. 2003;2(2):206-10.

31. Salizzoni M, Andorno E, Bossuto E, Cerutti E, Livigni S, Lupo F, et al. Piggyback techniques versus classical technique in orthotopic liver transplantation: a review of 75 cases. Transplant Proc. 1994;26(6):3552-3.

32. Savier E, Brustia R, Golmard JL, Scatton O. Influence of 4 preservation solutions on ICU stay, graft and patient survival following liver transplantation. J Visc Surg. 2020;157(2):87-97.

33. Khalil A, Ganesh S, Hughes C, Tevar AD, Hasche JJ, Esper S, et al. Evaluation of the enhanced recovery after surgery protocol in living liver donors. Clin Transplant. 2018;32(8):e13342.

34. Clevenger B, Mallett SV. Transfusion and coagulation management in liver transplantation. World J Gastroenterol. 2014;20(20):6146-58.

35. Hartmann M, Szalai C, Saner FH. Hemostasis in liver transplantation: Pathophysiology, monitoring, and treatment. World J Gastroenterol. 2016;22(4):1541-50.

36. Akamatsu N, Sugawara Y, Nakazawa A, Nishioka Y, Kaneko J, Aoki T, et al: Hemostatic status in liver transplantation: association between preoperative procoagulants/anticoagulants and postoperative hemorrhaging/thrombosis. Liver Transp/ 2015, 21(2):258-265.

37. Hesse UJ, Berrevoet F, Troisi R, Pattyn P, Mortier E, Decruyenaere J, et al. Hepato-venous reconstruction in orthotopic liver transplantation with preservation of the recipients' inferior vena cava and veno-venous bypass. Langenbecks Arch Surg. 2000;385(5):350-6.

38. Lee HC, Yoon SB, Yang SM, Kim WH, Ryu HG, Jung CW, et al: Prediction of Acute Kidney Injury after Liver Transplantation: Machine Learning Approaches vs. Logistic Regression Model. J Clin Med 2018, 7(11).

39. Lebrón Gallardo M, Herrera Gutierrez ME, Seller Pérez G, Curiel Balsera E, Fernández Ortega JF, Quesada García G. Risk factors for renal dysfunction in the postoperative course of liver transplant. Liver Transpl. 2004;10(11):1379-85.

40. Arudchelvam J, Bartlett A, McCall J, Johnston P, Gane E, Munn S. Hepatic venous outflow obstruction in piggyback liver transplantation: single centre experience. ANZ J Surg. 2017;87(3):182-5. 
41. Steib A, Saada A, Clever B, Lehmann C, Freys G, Levy S, et al. Orthotopic liver transplantation with preservation of portocaval flow compared with venovenous bypass. Liver Transpl Surg. 1997;3(5):518-25.

42. Belghiti J, Ettorre GM, Durand F, Sommacale D, Sauvanet A, Jerius JT, et al. Feasibility and limits of caval-flow preservation during liver transplantation. Liver Transpl. 2001;7(11):983-7.

43. Zanetto A, Rodriguez-Kastro KI, Germani G, Ferrarese A, Cillo U, Burra P, et al. Mortality in liver transplant recipients with portal vein thrombosis - an updated meta-analysis. Transpl Int. 2018;31(12):1318-29.

44. Englesbe MJ, Kubus J, Muhammad W, Sonnenday CJ, Welling T, Punch JD, et al. Portal vein thrombosis and survival in patients with cirrhosis. Liver Transpl. 2010;16(1):83-90.

45. Yerdel MA, Gunson B, Mirza D, Karayalçin K, Olliff S, Buckels J, et al. Portal vein thrombosis in adults undergoing liver transplantation: risk factors, screening, management, and outcome. Transplantation. 2000;69(9):1873-81.

46. Khan S, Silva MA, Tan YM, John A, Gunson B, Buckels JA, et al. Conventional versus piggyback technique of caval implantation; without extra-corporeal veno-venous bypass. A comparative study. Transpl Int. 2006;19(10):795-801. 